\title{
Hydrogen-Free Carburization on the Surface of Commer- cial Purity Titanium by Equipotential Hollow-Cathode Glow Discharge
}

\author{
Zhao Yun ${ }^{1,2}$, Zhang Yulin ${ }^{1}, \quad$ Zeng Yun ${ }^{3}, \quad$ Chen Fei $^{1}$ \\ ${ }^{1}$ Beijing Institute of Petrochemical Technology, Beijing 102617, China; ${ }^{2}$ University of Science and Technology Beijing, Beijing 100083, China; \\ ${ }^{3}$ Beijing University of Chemical Technology, Beijing 100029, China
}

\begin{abstract}
The treatment of hydrogen-free carburization was applied on commercial purity titanium by the technology of equipotential hollow-cathode glow discharge at the commercial purity titanium phase transition temperature. The morphology, distribution of composition and phase composition were analyzed by the scanning electron microscope, the energy dispersive spectrometer, the X-ray diffraction, respectively; the tribology capability of the sample was studied by the friction and wear tester; the corrosion resistance of the samples in $3.5 \% \mathrm{NaCl}$ solution was studied under the room temperature static condition by the electrochemical workstation. The results show that the high hardness alloy layer forms on the commercial purity titanium surface by the treatment of hydrogen-free carburization, and the maximum thickness of the carburized layer is $7.5 \mu \mathrm{m}$; and the maximum $\mathrm{HV}_{0.2}$ hardness is $12.98 \mathrm{GPa}$, which is 5.43 times of that of the substrate. Due to the improved surface hardness, the wear resistance on the surface of the sample increases significantly, and the average friction coefficient is only 0.312 , which obviously decreases compared with 0.746 of the original sample. The minimum annual corrosion rate of the samples is $1 / 11$ of the original sample in $3.5 \% \mathrm{NaCl}$ solution. So the wear resistance and corrosion resistance obviously improve in the premise of keeping the mechanical properties of the substrate.
\end{abstract}

Key words: commercial purity titanium; equipotential hollow-cathode glow discharge; hydrogen-free carburization; wear resistance; corrosion resistance

Commercial purity titanium possesses low hardness and poor wear resistance, which restricts its application in aerospace, petrochemical, power and other daily necessities in industry $^{[1-4]}$. Improving the surface hardness of commercial purity titanium is a necessary way to enhance its wear resistance $^{[5-7]}$. Surface modification technology is widely used $^{[8-10]}$, and the technology of hydrogen-free carburization is an effective method to enhance the titanium surface hardness $^{[11]}$. Hydrogen-free carburization technology puts carbon element into the surface of the titanium, forming alloy layer to improve the surface property of the workpiece. And this method avoids hydrogen embrittlement of titanium ${ }^{[12,13]}$. The technology has achieved good results that the hydrogen-free carburization layer on the surface of Ti6Al4V alloy prepared by plasma glow discharge surface metallurgy improves its wear resistance and corrosion resistance ${ }^{[14]}$. Usually the temperature of the surface treatment by plasma glow discharge is high, and it is above the temperature of phase transition, which has a certain impact on the mechanical properties and size of the workpiece. In the present paper, the equipotential hollow cathode glow discharge technique by a special structure of the graphite source pole is used for the hydrogen-free carburization on the surface of commercial purity titanium below the phase transition temperature, which can not only

Received date: May 13, 2016

Foundation item: Beijing Institute of Petrochemical Technology Breeding Project of Outstanding Academic Leaders (BIPT-BPOAL-2013)

Corresponding author: Chen Fei, Ph. D., Associate Professor, Beijing Institute of Petrochemical Technology, Beijing 102617, P. R. China, Tel: 0086-10-81292097,

E-mail: chenfei@bipt.edu.cn

Copyright (C 2017, Northwest Institute for Nonferrous Metal Research. Published by Elsevier BV. All rights reserved. 
improve the surface physical and chemical properties but also maintain the good comprehensive mechanical performance of the substrate.

\section{Experiment}

It makes the argon ionize, resulting in the production of $\mathrm{Ar}^{+}$and that bombard workpiece surface at low vacuum condition using the equipotential hollow cathode glow discharge technology. The acicular source and the cover bodies are made of graphite, and the multilayer covers can stabilize the carburizing atmosphere and increase the carbon concentration. Using the effect of equipotential hollow-cathode between the acicular sources, the carbon element of the source can be sputtered to the workpiece's surface. The composition and microstructure were changed when the $\mathrm{Ar}^{+}$ bombard the workpiece's surface. Therefore the workpiece's surface can be activated, leading to the adsorption and diffusion of the carbon elements. Ultimately the workpiece's surface became the deposited layer and carburized layer. Fig.1 is the device schematic which is the schematic of equipotential hollow cathode plasma glow discharge surface alloying.

Table 1 shows the process parameters of the samples. The hydrogen-free carburization treatment was applied on commercial pure titanium TA1 by the technology of equipotential hollow cathode glow discharge. The time is from 3 to $5 \mathrm{~h}$, the temperature is from 750 to $800{ }^{\circ} \mathrm{C}$, the working voltage is from 550 to $660 \mathrm{~V}$ and the current is from 3.0 to $5.0 \mathrm{~A}$. The duty cycle of the power is $35 \%$ and the gas flow is $100 \mathrm{~cm}^{3} / \mathrm{min}$, the air pressure is $35 \mathrm{~Pa}$. Fig. 2 is the discharging phenomenon.

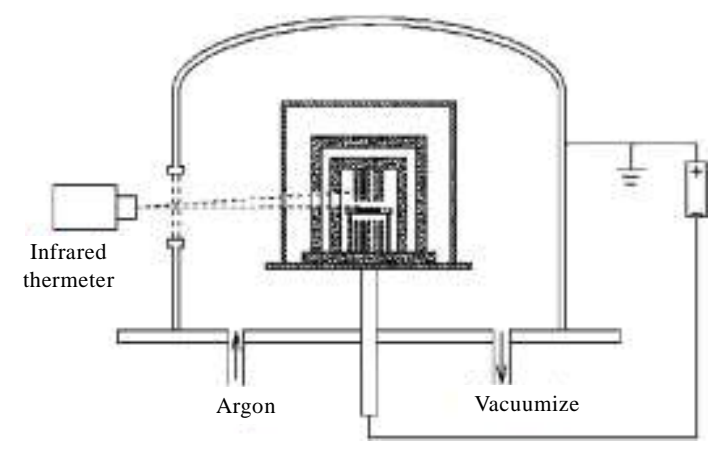

Fig.1 Schematic of equipotential hollow cathode plasma glow discharge surface alloying

Table 1 Processing parameters of each sample (No.1 is the original sample)

\begin{tabular}{cccccccc}
\hline No. & 1 & 2 & 3 & 4 & 5 & 6 & 7 \\
\hline Temperature $/{ }^{\circ} \mathrm{C}$ & - & 750 & 750 & 750 & 800 & 800 & 800 \\
Time/h & - & 3 & 4 & 5 & 3 & 4 & 5 \\
\hline
\end{tabular}

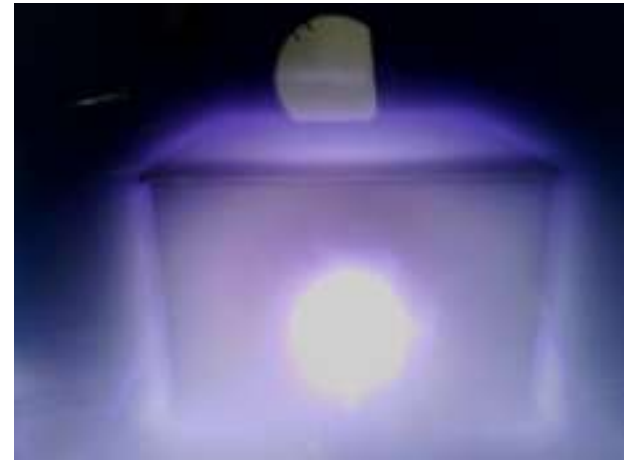

Fig.2 Phenomenon of hydrogen-free carburization by equipotential hollow-cathode glow discharge

The microstructure of the surface and the cross-section, and the composition distribution of the cross-section of the carburized layer and the wear trace on the surface were studied by SSX-550 scanning electron microscope; the phase composition of the carburized layer was studied by D8 FOCUS X-ray diffraction; the microhardness of sample was tested by HMV-1T microhardness tester; the electrochemical corrosion experiment was analyzed by CS360 electrochemical workstation; the rotating friction test was studied by the MS-T3000 friction and wear tester. The followings are the friction processing parameters: the material of the pressure head for the experiment is $\mathrm{GCr} 15$, the hardness is $62 \mathrm{HRC}$, the environment temperature is $25^{\circ} \mathrm{C}$, the relative humidity is $35 \%$, the load is $1.96 \mathrm{~N}$, the experimental time is $10 \mathrm{~min}$, the rotating speed of the sample stage is $500 \mathrm{r} / \mathrm{min}$ and the radius of grinding crack is $4 \mathrm{~mm}$.

\section{Results and Discussion}

\subsection{Microstructure and phase composition of carbu- rized layer}

Fig.3 shows the cross-section morphology of sample 7 . The thickness of the carburized layer is about $7.5 \mu \mathrm{m}$. During the process of hydrogen-free carburization, the specimen's surface adsorbs carbon elements which are sputtered from the carbon source pole and the surface carbon concentration gradually increases and the elements diffuse inside gradually, and the carburized layer forms. The speed of the carbon depositing on titanium surface is larger than that of carbon from the surface of titanium penetrating the interior, eventually which forms a layer of the carbon deposition.

Fig. 4 shows the results of EDS line analysis of the carburized cross-section. The carbon element content is the gradient distribution on the carburized cross-section of commercial purity titanium after hydrogen-free carburization treatment. The content of the carbon element is the highest in the surface, and the content of carbon element of 


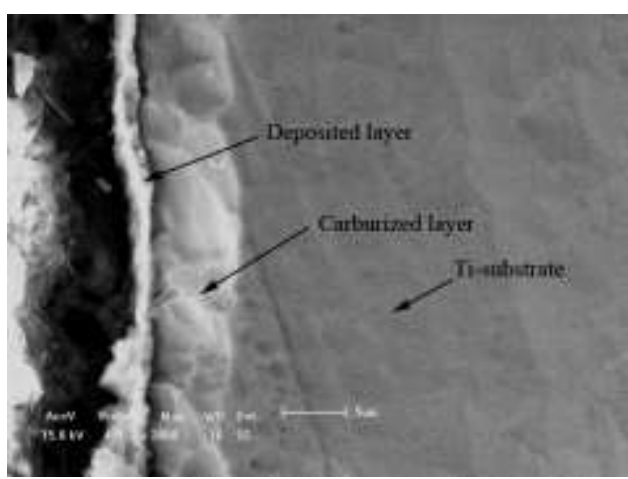

Fig.3 Cross-section morphology of No.7

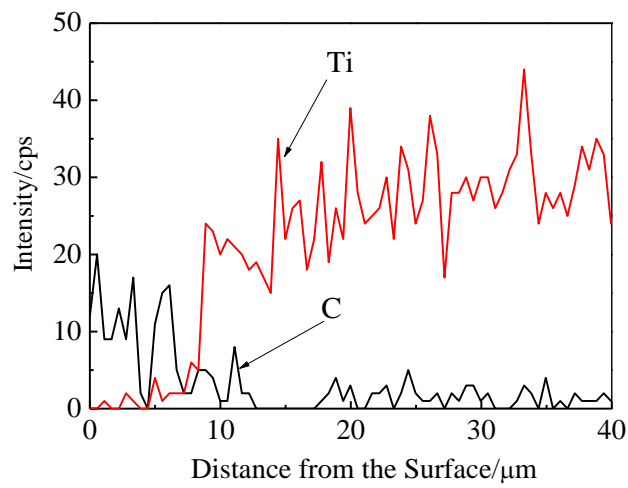

Fig.4 Composition distribution curves on cross-section of No.7

carburized layer is higher than the substrate obviously. The content of carbon element is down gradient, because a large number of $\mathrm{Ar}^{+}$bombard the surface and the carbon elements have strong energy implantation on the titanium surface, so with more surface defects on the surface, the corbon elements have the bigger diffusion coefficient. And the carbon elements that have energy easily diffuse into the interior. As the thickness increases, the content of the Ti element rises and tends to be steady inside the substrate. The region of the high concentration of carbon elements in the composition distribution curve is the carburized layer, and the depth is about $7.5 \mu \mathrm{m}$.

Fig.5 shows the surface morphology of sample No.4. The surface of the specimen is rough.

Fig. 6 shows the XRD patterns of carburized layer for samples No.2, No.3 and No.4. The patterns show that the main diffraction peaks of the No.2 corresponding to the phase structure is TiC. Through the change of the relative intensity of the diffraction peak it can be qualitatively determined by the change of the content of the phase. Fig. 6 shows that with the increase of the processing time, the intensity of the diffraction peak of TiC increases gradually at the same temperature, while the intensity of the diffraction

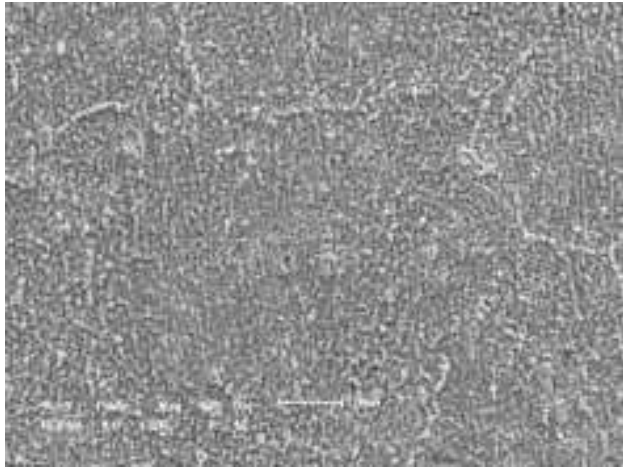

Fig.5 Surface morphology of hydrogen-free carburization layer for No.4

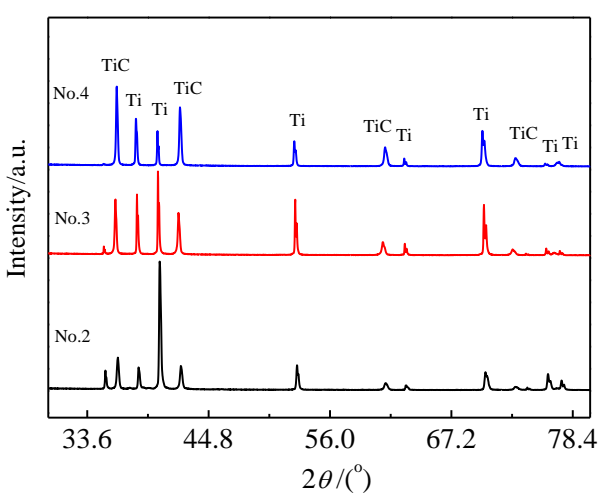

Fig.6 XRD patterns of carburized layer under different processing time

peak for the original sample $\mathrm{Ti}$ becomes lower and it indicates that the content of TiC increases. This is because with the increase of the processing time, the carburized layer is thicker.

\subsection{Wear resistance test}

The surface microhardness of each sample is shown in Fig.7. The results show that the microhardness $\mathrm{HV}_{0.2}$ of the original sample is $2.39 \mathrm{GPa}$, but the minimum microhardness $\mathrm{HV}_{0.2}$ of the samples that are processed is $5.57 \mathrm{GPa}$, the maximum microhardness $\mathrm{HV}_{0.2}$ is $12.98 \mathrm{GPa}$ for sample 7, which increases 2.33 times and 5.43 times than that of the original sample, respectively. Fig. 7 shows that the surface microhardness of the samples increases gradually with the increasing of the processing temperature and time. That's because the diffused rate of carbon atom is accelerated with the increasing of the processing temperature and the thickness of the carburizing layer increases with the extended time at the same processed temperature, which ultimately leads to the improving of the surface hardness of the samples.

Fig. 8 are the curves of the friction coefficient-test time of samples for No.1, No.4 and No.7. All the friction coeffi- 


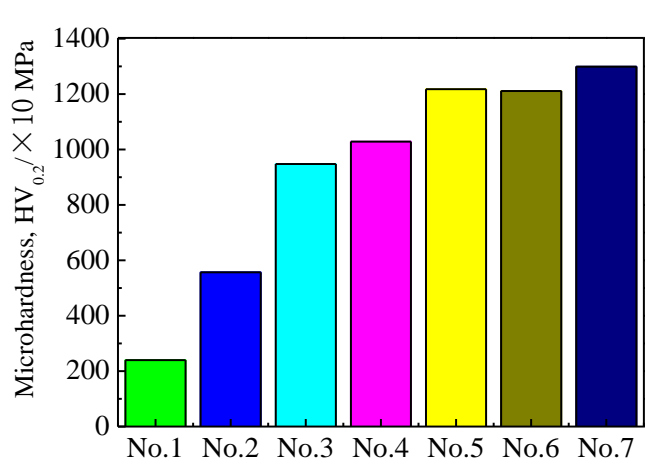

Fig.7 Surface hardness of each sample

cients of the samples have experienced a rapid increasing stage at the initial stage of the experiment and the friction coefficients stabilize after a period of time. All the friction coefficients of the samples which are processed by the hydrogen-free carburization are lower than that of the original sample, so the carburized layer has the higher wear resistance at room temperature under dry friction condition. The carbon element is injected, which has the effect of solid solution strengthening and improves the hardness of the samples' surface. At the same time, the hard phase of $\mathrm{TiC}$ is formed on the purity titanium TA1 substrate, thus improving the wear resistance of the samples' surface further. Table 2 shows that the wear resistance of the samples' surface is significantly improved because the improvement of the hardness of the surface and the friction coefficients of the carburization samples are less than that of the original sample. With the increase of the processing temperature, the friction coefficient gradually declines and the average friction coefficient of the sample 7 is only 0.312 , which significantly decreases compared with the original friction coefficient of 0.746 .

Fig.9 shows the wear scar morphologies of the sample No.1 and No.4. The original sample No.1 is adhesive wear,

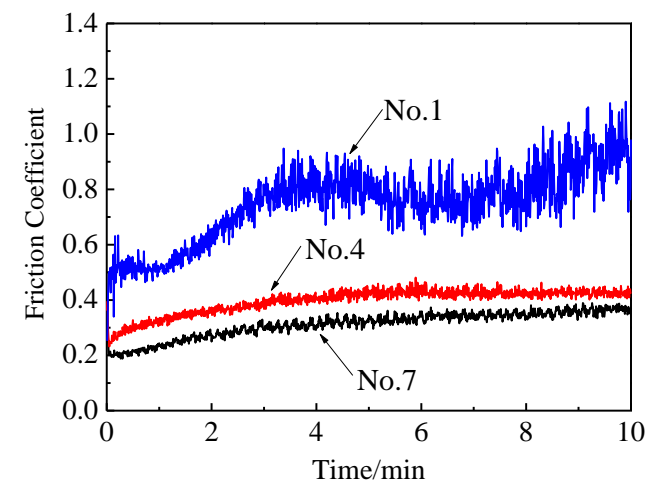

Fig.8 Friction coefficient of samples for No.1, No.4 and No.7
Table 2 Maximum and average friction coefficient of samples for No.1, No.4 and No.7

\begin{tabular}{ccc}
\hline No. & $\begin{array}{c}\text { Maximum friction } \\
\text { coefficient }\end{array}$ & $\begin{array}{c}\text { Average friction } \\
\text { coefficient }\end{array}$ \\
\hline 1 & 0.840 & 0.746 \\
4 & 0.481 & 0.396 \\
7 & 0.389 & 0.312 \\
\hline
\end{tabular}

and there are many furrows on the surface, so the wear is very serious. Oppositely, the carburized sample No.4 is hard wear, and there is a little wear trace. So the carburized layer is very hard and the wear resistance improves significantly.

\subsection{Electrochemical corrosion}

The electrochemical corrosion experiments were tested on No.1, No.2 and No.3. The 3.5\% NaCl solution was used as corrosion liquid, the reference electrode was saturated calomel electrode, the auxiliary electrode was platinum electrode, the experimental temperature was $25^{\circ} \mathrm{C}$, the area of the working electrode was $1 \mathrm{~cm}^{2}$ and the scanning rate was 0.5 $\mathrm{mV} / \mathrm{s}$ by the steady-state electrokinetic potentials canning method. Fig.10 shows each sample's polarization curve in $3.5 \% \mathrm{NaCl}$ solution. The corrosion current and the electrochemical corrosion data are in Table 3 .

Fig.10 shows that the corrosion potentials of the hydrogen-free carburized samples are higher than that of the original sample. The corrosion current density and the corrosion rate is far lower than those of the original sample, and the lowest corrosion rate is $2.35 \times 10^{-4} \mathrm{~mm} / \mathrm{a}$ of No.3 sample,

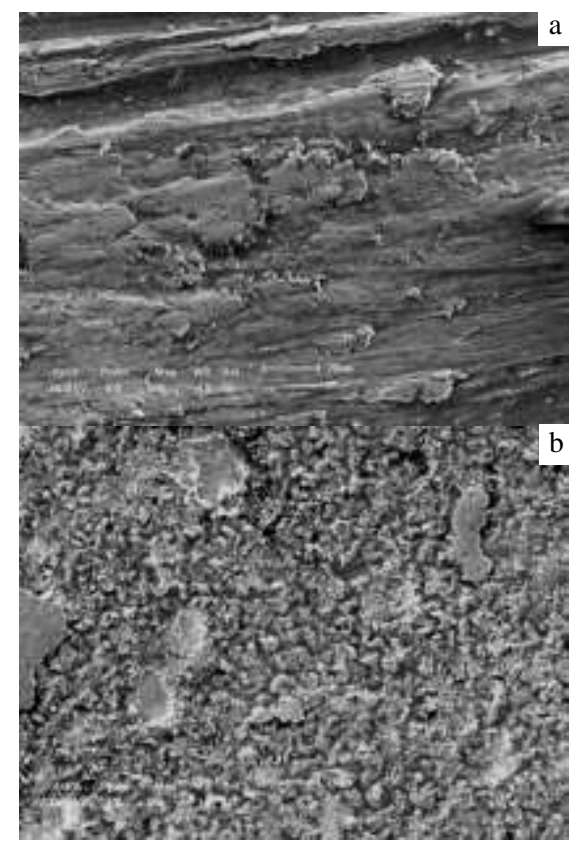

Fig.9 Wear scar morphologies of samples for No.1 (a) and No.4 (b) 


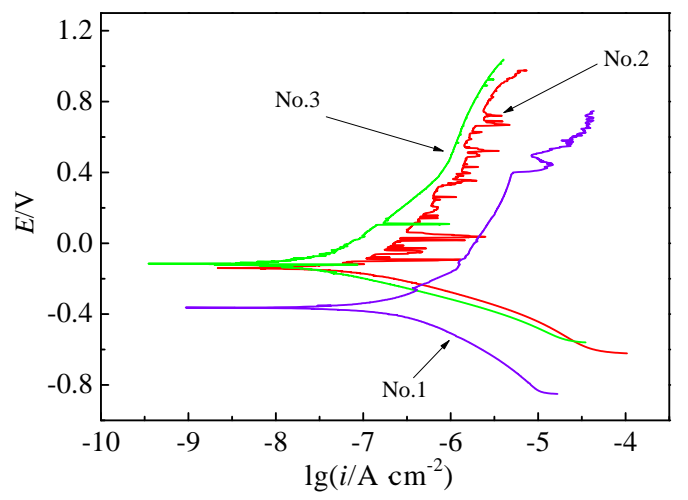

Fig.10 Polarization curves of the samples for No.1, No.2 and No.3 in $3.5 \% \mathrm{NaCl}$ solution

Table 3 Data of electrochemical corrosion in $3.5 \%$ $\mathrm{NaCl}$ solution

\begin{tabular}{cccc}
\hline No. & $\begin{array}{c}\text { Corrosion current } \\
\text { density/A } \cdot \mathrm{cm}^{-2}\end{array}$ & $\begin{array}{c}\text { Corrosion } \\
\text { potential/V }\end{array}$ & $\begin{array}{c}\text { Corrosion } \\
\text { rate } / \mathrm{mm} \cdot \mathrm{a}^{-1}\end{array}$ \\
\hline 1 & $6.96 \times 10^{-5}$ & -0.38 & $2.28 \times 10^{-3}$ \\
2 & $6.00 \times 10^{-5}$ & -0.15 & $1.96 \times 10^{-3}$ \\
3 & $7.20 \times 10^{-6}$ & -0.11 & $2.35 \times 10^{-4}$ \\
\hline
\end{tabular}

which is about $1 / 11$ that of the original sample No.1. The data in Table 3 shows that the corrosion potential of samples No.2, No.3 increases gradually with the increase of the time, and the corrosion rate decreases gradually with the increase of the time. The corrosion rates of the above samples in $3.5 \% \mathrm{NaCl}$ solution show that the corrosion resistance gradually strengthens with the increasing of the hydrogen-free carburization time.

\section{Conclusions}

1) Equipotential hollow cathode glow discharge technology can be used on the commercial purity titanium TA1, which forms the carburized layer.

2) Due to the improved surface hardness, the wear resistance increases significantly, while with the increase of processing temperature, the dry friction coefficients of the samples gradually decreases.

3) With the increase of the processing time, the corrosion resistance improves gradually.

\section{References}

1 Boyer R R. Mater Sci Eng A[J], 1996, A213:103

2 Shira C, Froes F H. Non-Aerospace Application of Titanium[M]. Warrendale: TMS, 1998: 331

3 Min X H, Emura S, Nishimura T et al. Materials Science and Engineering [J], 2010, 527(21-22): 5499

4 Li Zhengxian, Liu Ruibin, Hua Yunfeng et al. Titanium Industry Progress[J], 2014, 31(1): 1(in Chinese)

5 Avelar-Batista J C, Spain E, Fuentes G G et al. Surface and Coatings Technology[J], 2006, 201(7): 4335

6 Ani Zhecheva, Wei Sha, Savko Malinov et al. Surface and Coatings Technology[J], 2005, 200: 2192

7 Gao Yukui. Applied Surface Science[J], 2011, 257: 7455

8 Li Zhengxian, Zhou Lian, Xu Zhong. Rare Metals Letters[J], 2004, 23(2): 26 (in Chinese)

9 Gao Yuan, Zhang Wei, Wang Chenglei et al. Transactions of Materials and Heat Treatment[J], 2011, 32(7): 130 (in Chinese)

10 Chen Fei, Zhou Hai, Pan Junde. Transactions of Materials and Heat Treatment [J], 2009, 30(4): 156 (in Chinese)

11 Ji Shouchang, Li Zhengxian, Du Jihong et al. Rare Metal Materials and Engineering[J], 2010, 39(12): 2152

12 Hua Yunfeng, Li Zhengxian, Yang Hao et al. Rare Metal Materials and Engineering [J], 2012, 41(12): 2131 (in Chinese)

13 Li Zhengxian, Du Jihong, Zhou Hui et al. Rare Metal Materials and Engineering[J], 2004, 33(11): 1174 (in Chinese)

14 Chen Fei, Zhou Hai, Zhang Yuefei et al. Tribology[J], 2005, 25(2):121 (in Chinese)

\title{
纯钛表面等电位空心阴极辉光放电无氢渗碳的研究
}

\author{
赵 云 ${ }^{1,2}$, 张玉林 ${ }^{1}$, 曾 云 $^{3}$, 陈 飞 ${ }^{1}$ \\ (1. 北京石油化工学院, 北京 102617) \\ (2. 北京科技大学, 北京 100083) \\ (3. 北京化工大学, 北京 100029)
}

摘 要: 在纯钛相变温度下, 利用等电位空心阴极辉光放电技术在纯钛表面进行无氢渗碳处理。分别利用扫描电子显微镜、能谱仪和X 射线衍射仪对试样的表面形貌、成分分布和相组成进行分析; 利用摩擦磨损试验仪对试样的摩擦学性能进行研究; 利用电化学工作站, 在室温静态条件下对试样在 $3.5 \% \mathrm{NaCl}$ 水溶液中的耐蚀性能进行研究。结果显示, 经过无氢渗碳处理, 在纯钛表面形成了高硬度的合金改 性层, 改性层的最大厚度是 $7.5 \mu \mathrm{m}$, 最大 $\mathrm{HV}_{0.2}$ 显微硬度为 $12.98 \mathrm{GPa}$, 是基体硬度的 5.43 倍。由于表面硬度的提高, 试样的耐磨性能也显 著增强, 试样的平均摩擦系数是 0.312 , 较原始试样的 0.746 明显降低。在 $3.5 \% \mathrm{NaCl}$ 水溶液中, 试样的最低年腐蚀速率是原始试样的 $1 / 11$ 。 因此, 在保证基体力学性能的前提下, 试样的耐磨耐蚀性能明显提高。

关键词：工业纯钛；等电位空心阴极辉光放电；无氢渗碳；耐磨性；而蚀性

作者简介: 赵 云, 男, 1986 年生, 博士生, 北京石油化工学院材料科学与工程学院, 北京 102617, 电话: 010-81292097, E-mail zhaoyun@bipt.edu.cn 